(2) It has been recently shown by Messrs. Stanton and Bairstow (Proceedings of the Institution of Civil Engineers, I906) that the primitive yield-point of a rolled or forged steel is usually an artificial figure, and is due to a stiffening caused by this mechanical treatment. Such is not the case with these alloys. Their primitive yield-point is the true one.

(3) The ductilities (considered as a product of the percentage elongation and reduction of area) of alloys containing from 0.1 per cent. to 7.35 per cent. of aluminium are very high and practically constant, even although the tenacity increases narkedly with rise of aluminium.

(4) The tenacity and ductility of the widely-known " aluminium bronze" or "gold," containing io per cent. of aluminium, have been found to be as good in the form of small chill castings as in the rolled bar, where an so per cent. reduction of area of the original ingot has been effected. So far as the authors have been able to learn, this result has no parallel. At their request, therefore, independent tests were instituted at the Broughton Copper Works, and these have confirmed the above result, which may have important practical consequences.

(d) The research has brought to light several striking instances of the profound influence of a small quantity of aluminium upon copper, notably in the tension tests, but especially in the torsion and electrical conductivity experiments. One-tenth of $\mathrm{I}$ per cent. raises the angle of twist of copper in torsion 90 per cent.; it lowers the electrical conductivity 23 per cent.

(e) The behaviour in torsional stress of the alloys containing from $0 \cdot x$ per cent. to 7.35 per cent. of aluminium is one of the outstanding features of the report.

$(f)$ The alloys containing from 5 per cent. to ro per cent. of aluminium have come well out of the dynamic stress tests. The particular merit of alloys Nos. 9 and 13 when tested in alternating stress is the close approximation of the maximum stress under which they will bear an unlimited number of reversals to the stress at the elastic limit as determined in a tensile test. In this respect they are markedly superior to the iron and steel specimens hitherto investigated.

Alloys Nos. 6, 9, and 13 stood up well when repeatedly stressed beyond the yield-point in Arnold's test. In fact, Prof. Arnold has informed the authors that "Alloy No. constitutes a record in its capacity of resisting alternations.

(g) At about 15 per cent. of aluminium the alloys are entitled to rank with quenched steels in hardness. Thus the hardness number of No. 17 ( $\times 5.38$ per cent.) in the cast state (untreated) is 539 , which is about that of a 0.45 per cent. carbon steel quenched in water at $20^{\circ} \mathrm{C}$. $\left(68^{\circ} \mathrm{F}.\right)$, and is only slightly lower than that of a 0.66 per cent. carbon steel similarly treated.

(h) In the corrosion tests, which were purposely made as severe as possible, alloys containing from $\mathrm{r}$ per cent. to ro per cent. of aluminium have shown themselves to be practically incorrodible by sea-water, whether alone or bolted to a plate of mild steel. In these tests they showed themselves superior both to Muntz metal and naval brass, which corroded appreciably. In tap water of medium temporary hardness the positions were exactly reversed.

(k) In view of the discussion in the previous report as to the trustworthiness of temperatures measured with a protected thermo-junction, the exact influence of the jacket (a fire-clay tube $1 / 16$ th jnch in thickness) between temperatures of about $1100^{\circ} \mathrm{C}$. and $550^{\circ} \mathrm{C}$. $\left(2012^{\circ} \mathrm{F}\right.$. and $1022^{\circ}$ F.) has been determined. "It has been found to cause a lowering of not more than $3^{\circ} \mathrm{C} .\left(5^{\circ} \cdot 4 \mathrm{~F}\right.$.) at the higher, and $9^{\circ} \mathrm{C} .\left(16^{\circ} \cdot 2^{\circ} \mathrm{F}\right.$.) at the lower temperature, and above $800^{\circ}$ C. $\left(1472^{\circ}\right.$ F.) comes within the experimental errors and uncertainties of the method.

(l) Finally, a special comment must be made on the truly extraordinary similarity in physical and merhanical qualities between alloy No. 13, which consists of 90.06 per cent. of copper +9.90 per cent. of aluminium, and Swedish Bessemer rolled steel of about 0.35 per cent. of carbon and thirty-eight tons per square inch ultimate tensile stress.

NO. I 948 , VOL. 75$]$

\section{A PROPOSED INTERNATIONAL ATTACK ON THE SIDEREAL PROBLEII.}

IN a brochure written by Prof. J. C. Kapteyn, of the Groningen Astronomical Laboratory, the author outlines the chief points of a very comprehensive attack, which he proposes should be made as soon as possible, on the main problems concerning the structure of the sidereal universe.

Whilst the "Carte du Ciel," parts of which are now approaching completion, gives us the relative projecteci positions of all the stars down to the elcventh masnitude and will, by duplication after a number of years, afford material for the accurate determination of proper motions, it leaves untouched the extremely important question as to the distribution of different stellar types in actual space Prof. Kapteyn proposes to supplement this enormous work by the preparalion of a Durchmusterung which shall contain all the necessary data for a preliminary discussion ot the structure of the universe. In fact, he proposes that in the same way that the geological has supplemented the geographical study of the earth, so shall an astrological supplement our astrographical study of the heavens; bu it is obvious that to attempt a scheme like this for th whole of the heavens at once would be to court failure. The plan would probably die of senile decay ere it shower sufficient results to have justified its existence. For thi reason, and acting on the advice of eminent astronomer who favour the idea of such a survey, Prof. Kapteyn limits his proposals to a number of selected areas of the sky. This would reduce the work immensely, and would probably lead to a first approximation of the truths which it is hoped to educe.

The general scheme is based on the method of "gauging " as carried out by the Herschels, only that now, in stead of considering simply the numbers of stars, every ascertainable fact in regard to the objects studied must be considered. The chief data to be obtained, as enumerated by the proposer of the scheme, are visual magnitudes, photographic magnitudes, spectral types, astronomical proper motions, radial velocities, and parallaxes, to which list he adds the determination of the amount of light received from different parts of the sky, as being a subject of great importance to the problem under consideration.

As Prof. Kapteyn points out, there are already sufficient data for the brighter stars, partially excepting parallax and photographic magnitudes, to allow of a fairly thorough statistical treatment, but much of this data needs a great amount of arrangement and classification ere it can be included in a homogeneous attack. The great need in such an inquiry as that proposed is the international study of the fainter stars. Work already completed, or now in hand, will take us down to the seventh or eighth magnitude for most of the elements named, but it is self-evident that, in any attempt to solve the riddle of sidereal struc ture, the Milky Way is an all-important feature, and therefore, far fainter magnitudes than this must be included.

Put into its briefest form, the scope of Prof. Kapteyn's proposals is :--" For 206 areas regularly distributed over the sky, and for another less extensive series of particularly interesting regions, to obtain astronomical data ot every kind for stars down to such faintness as it will be possible to get in a reasonable time." The 206 areas first named come under the designation of "the systematic plan," and are again divided into two classes, the first of which would comprise 118 , and the second eighty-eight areas. These are so arranged that the first class might be completed independently of the second, and would furnish sufficient data for a first approximation. Then, if there were evidence that this could be executed in reasonable time, the second class might be intercalated without interfering with the other, except to provide further data which would, in all probability, enhance the value of the fina! 1906. 
results to an cxtent incommensurable with the extra labour involved.

The 200 areas would include 400 square degrees of the sliy, and this full scheme would entail the following labours:-1he determination of the rough positions and sharply defined photographic magnitudes of some 200,000 stars; visual magnitudes for the same 200,000 ; the determination of the accurate proper motions, to within $o^{\prime \prime}$ or in each coordinate, of some twenty thousand of these objects. For the same twenty thousand, parallaxes are necessary, and for as many of them as is possible the class of spectrum and the radial velocities must be determined. linally, the determination of the total amount of light received from different parts of the sky would complete a set of homogeneous dala from which undreant-of additions to our knowledge of the sidereal universe might accrue.

In addition to this "systematic plan," Prof. Kapteyn, after much correspondence and discussion with a number of cminent astronomers, has decided on a scheme for the elucidation of "special areas." This scheme includes forty-six areas, such as those in the Milky Way which show intense variations of star-density, the rifts and branches of the Milky Way, and extra-galactic areas where nebula or strong contrasts in star-density are preponderant.

Many interesting devices to further the plan are discussed by Prof. Kapteyn, e.g. The determination of colour, and hence the probable spectrum class, from the comparison of the photographic and visual magnitudes in the cascs whrre the stars are so faint that these leatures cannot be deformined by the usual methods; again, the dotermination of proper motions and parallaxes from plates exposed a second time after an interval of some years. Possibly l'rof. Wolf's stereo-comparator method of determining proper motions would materially curtail the interval necessary between the two exposures.

Considring a few details, it is seen that the scheme includes:---(1) 07 to cxposures on 2620 plates, in addition to the plates for the dutermination of the radial velocities of three or four slandirds in each area. (It is intended that the bulk of the radial velocities shall, if possible, be determined by one of the wholesale prismatic-camera methods such as those proposed by IIerr Orbinsky, Prof. E. C. Pickering, and l'rof. Comstock.) (2) Visual observations of 3024 standard magnitudes, the defermination of the masnitudes and positions of 200,000 stars, and the meridian observations of some 2600 stars for propermotion standards. (3) The moasuring of nearly $i_{2}^{t}$ million images.

Prof. Kapteyn, with all his experience, is quite ready, should the essential funds be forthcoming, to undertake a greater part of the measuring work, and could, at present, undertake to perform half his proposed share. A numbor of other well-known astronomers, as may be seren from the letters which he publishes at the end of his brochure, are definitely and enthusiastically in favour of the project, and are willing to grant what aid is in their power, so that the scheme cannot be looked upon as immature or as entailing insuperable difficulties.

Accepting for the moment that the plan, in its entirety, is feasible, the possibililies attached to the discussion of the results are obviously infinite. In some fifty or a hundred years, the "Carte du Ciel," if repeated, will probably afford a series of definitive proper motions which can then be discussed from the sidereal structure standpoint, but of the spectral layers in the visible universe it would leave us in almost total ionorance. On the other hand, the results from Prof. Kapteyn's plan would probably afford all the information attainable by human effort of the sidereal strata, or groups, or drifts, or a thousand and onc other features.

As an earnest of what might accrue from such a discussion, one mav cite the remarkable result recently derived by Mr. Eddington from the analysis of the relatively meagre data of the Greenwich-Groombridge proper motions (see Xature, No. 1938, p. 182 , December 20 , 1906), a result Srst derived, in a qualitative form, by Prof. Kapteyn himself from a discussion of the Bradley proper motions.

NO. I948, VOL. 75$]$

\section{UNIVERSITY AND EDUCATIONAL INTELLIGENCE.}

OXFORD.-At a meeting of members of convocation in Magdaten College on February 23, which had been summoned by the Vice-Chancellor to consider the election of a Chancellor of the Lniversity, there seemed to be a majority in favour of the nomination of Lord Curzon.

The published accounts of the common university fund for 1906 show that the income for that year was 6937 . and the expenditure $6395 \%$, of which sum $35 \%-l$. Was devoted to scientific objects.

Cambridge.- The Smith's prizes have been awarced for the following essays:---"Fluorescence," G. R. BlancoWhite; "The Systematic Motions of the Stars," A. S. Eddington; "The Bending of Waves Round a Iarge Opaque Sphere and some Associated l'roblems," $\mathrm{J}$. W. Nicholson; "The Variation of the Absorption Bands in the Spectrum of a Crystal under the Action of a Magnetic lield," W. M. Page. The names are arranged in alphabetical order. The essay on "Some Problems on the Dillraction of Electric Waves," by II. J. Priestley, is awarded honourable mention.

H. R. Hassè has been elected to the Isaac Newton studentship, tenable from April 15, 1907, to April I5, 1910. The student will carry on a course of research in physical optics.

W. Spens has been elected fellow at Corpus Christi Collegge, and has also been appointed director of natural science studies in the college.

Dr. Harmer, the superintendent of the Museum of Zoology, announces the receipt of a cast of a skeleton of Diprotodon australis, presented by Dr. E. C. Stirling, F.R.S. director of the South Australian Museum at Adelaide. Dr. Harmer also records the gift of a valuable consignment of some nine skeletons and forty skulls and skins of mammals, mostly antelopes, from tropical Africa, presented by Mr. C. B. C. Storey, of Clare College.

The Cavendish Laboratory Extension Syndicate has proposed plans for the new laboratory running along firee School Land, which will cost between joool. and $8,300 l$. Towards defraying the cost of this building there is available Lord Ravleigh's gift of 5oool. out of the Nobel prize, and P'rof. Thomson is able to find 2oool. from the laboratory funds.

The recommendation of the general board of studies that a university lecturer in pathology be appointed, in connection with the special board for medicine, with an annual stipend of $100 l$. payable out of the common university fund, will be brought before the Senate on March 0

It is proposed to nominate Prof. A. Thomson to be a member of the board of electors to the professorship of anatomy; Sir E. C. Perry, a member of the 5oard of clectors to the Downing professorship of medicine; Prof. Graham Kerr, an elector to the professorship of zoology; Dr. Anderson, an elector to the chair of physiology; Prof. Midelleton, an elector to the Drapers' professorship of agriculture; and Prof. Langley, to that of botany.

The local examination. ond lectures srndirate has appointed E. A. Parkyn and D. H. S. Cranage as delegates at the International Congress on School itygiene io be held in London in Aurust.

Mr. J. J. Lister has been appointed a manager of the Balfour fund until June, 1909, in succession to the late Sir Michael Foster.

Mr. F. A. Potts has been nominated to occupy the University table at the laboratory of the Marine Biological Association at Plymouth for one month during the ensuing Faster vacation.

THE Mercers' Company has made a donation of fifty guincas, and the Grocers' Company one of ten guineas, to the South-Eastern Agricultural College.

Ar the South-Western Polytechnic on March is the Lord Alverstone, G.C.M.G., Lord Chief Justice of England, will present prizes and certificates to students of evening classes and of the day college. 